Running Head: MENTAL REPRESENTATIONS OF ATHEISTS AND THEISTS

Atheist horns and religious halos: Mental representations of atheists and theists

Jazmin L. Brown-Iannuzzi ${ }^{1 *}$, Stephanie McKee ${ }^{1 *}$, Will M. Gervais ${ }^{1}$

${ }^{1}$ University of Kentucky

*Represents equal contributions

Word Count: 3,815 (out of 5,000) 


\begin{abstract}
Theists - regardless of religious affiliation - receive the benefit of being stereotyped as trustworthy and moral (Hall, Cohen, Mayer, Varley, \& Brewer, 2015), whereas atheists are viewed as untrustworthy and morally uninhibited (Gervais, 2014a; Gervais, Shariff, \& Norenzayan, 2011). The extreme divergence between the stereotypes of theists and atheists suggests that mental images of the two groups may also diverge. We investigated whether people have biased mental images of theists and atheists. The results suggests that mental images of theists are associated with more positive attributes than images of atheists (Study 1), and these mental images influence who is believed to behave morally and immorally (Study 2). Together, the findings suggest that mental images may represent a subtle mechanism reinforcing groupbased prejudices (both negative and positive).
\end{abstract}

WORD COUNT: 127 


\section{Atheist horns and religious halos: Mental representations of atheists and theists}

Sin is a thing that writes itself across a man's face. It cannot be concealed...If a wretched man has a vice, it shows itself in the lines of his mouth, the droop of his eyelids, the moulding of his hands even.

Oscar Wilde, The Picture of Dorian Gray

The religious freedom afforded to Americans by the First Amendment has created a rich and diverse religious culture. Despite the wide range of religious affiliations present in the U.S., there still exists at least one often-heated religious division: those who believe in God (or gods) and those who do not. Although the vast majority of Americans self-report believing in God or a higher power (Gallup, 2015), the number of atheists ${ }^{1}$ is rising dramatically and may be systematically underreported (Gervais \& Najle, 2017). Optimistically, we might expect that the increasing prevalence of atheists may reduce anti-atheist prejudice (Gervais, 2011), perhaps through positive intergroup contact (Pettigrew, 1998). However, anti-atheist prejudice shows few to no signs of abating (Gervais, 2014a; Brown-Iannuzzi, Najle, \& Gervais, Under Review).

Atheists are one of the most hated groups in the U.S. Although religious individuals regardless of one's religious affiliation - receive the benefit of being stereotyped as trustworthy and moral (Hall, Cohen, Mayer, Varley, \& Brewer, 2015), atheists are viewed as untrustworthy and morally uninhibited (Gervais, 2014a; Gervais, Shariff, \& Norenzayan, 2011). The extreme divergence between stereotypes of theists and atheists suggests that mental images of the two groups may also diverge. Spontaneous mental images of theists may reflect positive attributes, such as trustworthy and moral, whereas mental images of atheists may reflect negative attributes, such as untrustworthy and immoral. These mental images are important because they may

\footnotetext{
1 "Atheist" merely means a person who disbelieves or lacks belief in the existence of a god or gods. We adopt this standard dictionary definition throughout.
} 
represent a subtle mechanism reinforcing group-based prejudices (both negative and positive). The current research investigates the mental images of theists and atheists.

\section{Perceiving Religiosity in a Face}

Human beings are particularly motivated to identify trustworthy individuals (e.g., Simpson, 2007). As social animals, humans need to cooperate in order to gain the benefits that the group produces, even if cooperation comes at a cost for the individual. Relatedly, people need to identify potential defectors because defectors may gain the benefits of the group without contributing to the group, and defectors can ultimately end up eroding group cohesion and cooperation (e.g., Sober \& Wilson, 1998). Together, group living motivates finding trustworthy individuals who will cooperate with the group.

Religiosity may be a proxy for trustworthiness because religious believers may fear punishment (now or in the afterlife) for social norm violations (Norenzayan et al., 2014). As long as people believe in a supernatural agent (such as God) who is omniscient, monitors behavior, and punishes social norm violators, then people may be motivated to cooperate and conform to social norms in order to avoid punishment. In this way, religious belief may have the same psychological and behavioral effects as fearing punishment from another person (e.g., Gervais, 2014; Gervais, Shariff, \& Norenzayan, 2011; Johnson \& Bering, 2006). As a result, people who fear punishment (either from another person or from a supernatural agent) may behave more prosocially, at least when their gods are made salient (e.g., Bering, McLeod, \& Shackelford, 2005; Shariff \& Norenzayan, 2007).

Not only may religion promote cooperation, but it may also serve as a signal of one's trustworthiness. For example, participants demonstrated greater trust in the "trust game" with others who identified as religious (Tan \& Vogel, 2008). Relatedly, people who signaled their 
religiosity, such as by fasting for religious reasons, were trusted more than people who did not signal their religiosity (Hall et al., 2015). Importantly, trust in the religious other did not depend on the religious affiliation of the other person. This suggests that overt signals of religiosity can increase interpersonal trust both within and across religious groups. Given that trust is one of the most valued characteristics for a relationship (Cottrell, Neuberg, \& Li, 2007), people may be motivated to identify religious others as especially trustworthy.

Religiosity can signal trust, but it may also be the case that trust (and other positive attributes) can in turn signal religiosity. One way that trust can signal religiosity is through a person's facial features. In fact, previous research has found that people tend to think that others with pronounced cheekbones, raised inner eyebrows, wide chins, and shallow nose sellions are trustworthy (Todorov, Baron, \& Oosterhof, 2008). We predict that mental images of theists would have gestalt facial physiognomies that display positive attributes, especially in the domains of morality and trustworthiness.

\section{Perceiving Atheism in a Face}

Atheism may be heuristically associated with immorality and untrustworthiness. Atheists are individuals who do not believe in a supernatural agent(s). Since atheists do not believe in a watchful God who punishes social norm violators, theists often conclude that atheists have less incentive to contribute to the group and thus treat atheists with suspicion (Gervais, 2013). Relatedly, many theists feel that belief in God is a necessary component of morality (e.g., Gervais, 2013, 2014a; Norenzayan \& Gervais, 2013). As a result, the lack of belief in God may signal distrust, immorality, and group defection to theists (Cook, Cottrell, \& Webster, 2015).

Atheists are widely perceived as untrustworthy (Gervais, 2013, 2014a; Gervais, Shariff, \& Norenzayan, 2011). In fact, atheists and rapists are equally as distrusted in the U.S. on at least 
one indirect measure (Gervais, Shariff, \& Norenzayan, 2011). This extreme distrust is also associated with explicit discriminatory desires. Atheists in America are more likely to be excluded than other minority groups (e.g., Muslims, homosexuals, and recent immigrants; Edgell, Gerteis, \& Hartmann, 2006), even though atheists are not part of a recognizably coordinated and cohesive group (e.g., Norenzayan \& Gervais, 2013). And, acts such as serial murder, necrobeastiality, and even cannibalism are viewed as being more representative of atheists than other groups (e.g., Muslims, Christians, Native Americans; Gervais, 2014). Together, this suggests that atheists are stereotyped as untrustworthy and immoral people for whom every unspeakable act is permitted.

The strong negative reaction to atheists suggests that people might spontaneously generate extremely negative mental images of atheists relative to theists. And, mental images of atheists and theists may inform judgments of who commits moral and immoral behaviors. These spontaneous mental images of atheists and theists are important because they suggest a subtle mechanism that can reinforce anti-atheist prejudice and pro-theist attitudes.

\section{Overview of current studies}

We investigated whether people have biased mental images of theists and atheists. Using a procedure to visually estimate participants' mental images, we tested two hypotheses. First, we hypothesized that mental images of a typical theist individual would depict an individual who exudes trust and other positive attributes, but mental images of a typical atheist individual would depict an individual who exudes distrust and other negative attributes (Study 1). Second, we hypothesized that an independent group of people, naive to how the images were generated, would assume the typical atheist image was more likely to act immorally (e.g., have sex with a dead chicken, etc.), and the typical theist image was more likely to act morally (e.g., volunteer at 
a soup kitchen, etc.; Study 2). All studies were pre-registered, and study materials and data are available through an online data repository. ${ }^{2}$ We report how we determined our sample size, all data exclusions (if any), all manipulations, and all measures in the studies. Together, these studies investigate whether negatively biased mental images of atheists may, in part, reinforce anti-atheist prejudice, and positively based mental images of theists reinforce pro-theist attitudes.

\section{Study 1 Method}

We conducted Study 1 in two phases: the image generation phase and the image rating phase. In the image generation phase, participants completed the reverse correlation task to generate the mental images of an atheist and religious person (Brown-Iannuzzi, Dotsch, Cooley, \& Payne, 2017; Dotsch \& Todorov, 2012; Dotsch, Wigboldus, Langner, \& van Knippenberg, 2008; Imhoff \& Dotsch, 2013; Krosch \& Amodio, 2014; Mangini \& Beiderman, 2004; Ratner, et al., 2014). The advantage of using the reverse correlation procedure is that this data-driven method allows us to infer perceivers' internal mental representations of an atheist and religious person.

In the image rating phase, we had a separate sample of participants rate the average images on two broad dimensions: demographics (e.g., gender) and traits (e.g., trustworthiness, morality). Importantly, the participants in this phase did not know how the images were generated, and the survey did not mention religion in reference to the images. Thus, any effects of religiosity could emerge spontaneously.

\footnotetext{
${ }^{2}$ Please find study pre-registration at the following web addresses: https://aspredicted.org/xpaz2.pdf (Study 1 image generation); http://aspredicted.org/blind.php? $\mathrm{x}=$ wqnf28 (Study 1 image rating); http://aspredicted.org/blind.php? $\mathrm{x}=99 \mathrm{i} 37 \mathrm{t}$ (Study 2). Data will be made publically available upon acceptance.
} 


\section{Image Generation Phase}

Participants. We recruited 377 American participants, but only 223 participants completed the survey (120 women, 103 men) from Amazon Mechanical Turk. All partial data was included in the analyses. The average age was 35.71 years $(\mathrm{SD}=10.75)$, and 141 reported believing in God or a higher power (82 reported not believing in God or a higher power). All measures and manipulations are reported below.

Procedure. This study utilized a reverse correlation task consisting of 400 critical trials. This task begins with a single "base face," which was a morphed composite of a Black man, Black woman, White man, and White woman (see Figure 1$){ }^{3}$ Then, we added random visual noise to this base face to create 800 variants. Participants were randomly assigned to the Atheist or Religious condition. On each trial, participants were presented with image pairs and were asked to select the image that "most looks like a person who does (not) believe in God."

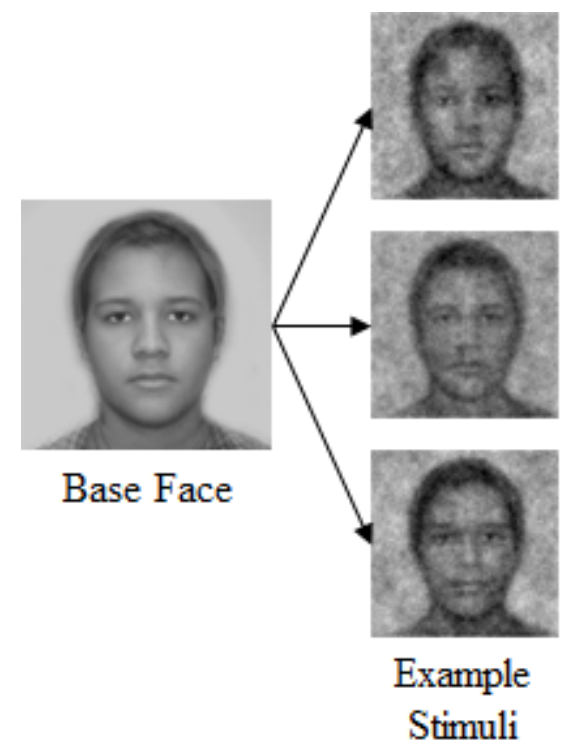

Figure 1. The base image used in the reverse correlation task and three examples of the stimuli.

\footnotetext{
${ }^{3}$ The stimuli used in the reverse correlations procedure are the same as used in a previous publication (BrownIannuzzi et al., 2017).
} 
After completing the reverse correlation task, participants were asked whether they believed in God or a higher power $(1=$ Yes, $0=$ No). For exploratory purposes, we created separate images for participants who did and did not believe in God. These images and subsequent analyses are presented in the Supplemental Online Materials. Participants also responded to the following demographic measures: age, gender, race/ethnicity, socioeconomic status, income, education, political party affiliation, and political ideology. Because we created an average image (see Image Processing below) - averaged across responses from the reverse correlation task and across participants - these demographic measures are not relevant for our main hypotheses, but were collected for solely descriptive purposes.

\section{Image Processing}

Using the R package rcicr 0.3.0 (Dotsch, 2015), we computed the average atheist and theist image. In the atheist condition, all of the selected images across all participants were averaged together to create the average atheist image. In the theist condition, all of the selected images across all participants were averaged together to create the average theist image. Averaging the selected images together amplifies the features they share with participants' mental representations and reduces the random variation in unshared features. The resulting average images are displayed in Figure 2.

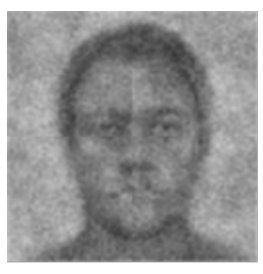

Average Atheist Image

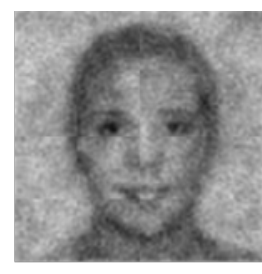

Average Theist Image

Figure 2. Average classification images. 


\section{Image Rating Phase}

To gauge the characteristics of the classification images, we had a separate sample rate the average atheist and theist images. Participants were randomly assigned to one of two rating conditions to minimize participant fatigue.

Participants. Given this mixed design, we needed at least 156 participants in each condition to have adequate power $(.80)$ to detect a small effect $(f=.10$; G*Power software, Faul, Erdfelder, Buchner, \& Lang, 2009). An attention check was included as the first question because past research suggests that such attention checks can improve data quality (Oppenheimer, Meyvis, \& Davidenko, 2009). All measures, manipulations, and exclusions are reported below.

Participants $(N=351)$ were recruited from Amazon Mechanical Turk. We excluded 19 participants from analyses because they failed the attention check. ${ }^{4}$ The final sample included 332 participants (186 women, 140 men, 6 failed to report gender). The average age was 37.17 years $(S D=12.83)$, and 253 reported believing in God or a higher power (73 reported not believing in God or a higher power, 6 failed to report).

Procedure. Participants were told they would rate a few images on a series of dimensions. Six of the images were filler images so that the comparison between the two images of interest would not be salient to participants. The critical images were the average atheist and religious images. Importantly, participants were not told how these images were created and there was no mention of religion or atheism. All images were randomly presented to avoid order effects.

\footnotetext{
${ }^{4}$ Including all participants, even those who failed the attention check, does not substantively change the results.
} 
In order to avoid fatigue, participants were randomly assigned to one of two conditions. In one condition, participants rated each image on gender, race, attractiveness, happiness, work ethic, likeability, competence, and warmth (on a 1 to 6 scale; higher numbers meant more White American, female, and higher on the listed attributes). In the other condition, participants rated each image on perceived religiousness, which served as a manipulation check. In addition, participants rated each image on perceived trustworthiness, morality, humanness, and hostility (all items measured on a 1 to 6 scale; higher numbers meant higher on the listed attributes).

After the ratings, participants completed demographic information - age, gender, subjective SES, income, education, race, religious behaviors (the frequency of attending church and praying), religion, and whether or not the participant believed in God or a higher power. These measures were collected to characterize the sample. Since the measures were not central to our hypotheses, they will not be discussed.

\section{Results}

We investigated whether the ratings of the average atheist image differed from the average theist image using repeated measures ANOVAs. Figure 3 presents the means and 95\% confidence intervals for the ratings of each image. Table 1 presents the specific mean values, effect sizes, and Bayes Factors (using the default priors set in JASP; JASP Version 0.8.0.0, 2016; Love, et al., 2015; Morey \& Rouder, 2015; Rouder, et al., 2012) for each set of ratings.

First, as a manipulation check, we investigated whether the theist image was perceived as more religious than the atheist image. As predicted, participants rated the theist image as appearing significantly more religious than the atheist image, $F(1,169)=166.18, p<.001$. 
We also investigated the stereotypes associated with each image. Consistent with our hypotheses and previous work (Gervais, 2014a), the atheist image was rated as significantly more untrustworthy, immoral, incompetent, and cold than the religious image, all $F$ 's $>130, p^{\prime} s$ $<.001$. Further, participants rated the atheist image as significantly more hostile, inhuman, and lazy than the religious image, all $F^{\prime} s>86, p{ }^{\prime}<.001$. We also explored a general valence effect and found that participants rated the atheist image as less likeable, happy, and attractive than the religious image, all $F$ 's $>295, p$ 's $<.001$.

For exploratory purposes, we also investigated the perceived gender and race of the atheist and religious images. We had no specific hypotheses, but we found that the religious image was rated as significantly more feminine and White than the atheist image, all $F$ 's $>44$, $p$ 's $<.001$. The race findings, though not predicted, may warrant future research. In regards to the gender rating, some research has found that women are slightly more religious and more likely to attend religious services than are men (Inglehart \& Norris, 2004; Murphy, 2016). The gender finding in the images may reflect awareness and/or the over perception this difference. In addition, women are often considered "pure," and this moral purity may be related to the perceived moral purity of religious individuals (Fiske \& Glick, 1995). However, we cautiously interpret these gender findings as they were not predicted, but may warrant future research.

Overall, the results suggest that participants were less positive toward the atheist image than they were toward the religious image. These findings are particularly noteworthy given that the participants did not know how the images were created or that they had to do with religious beliefs. The attributes stereotypically associated with atheists and theists were apparent in the images. In fact, participants rated the atheist image as untrustworthy and immoral, and these effect sizes were larger than the perceived religiosity effect size. This is interesting because the 
findings suggest that when people imagine a religious individual (vs. atheist), a naive sample are clearly identifying traits commonly associated religiosity. However, we did not test whether mental images of the average atheist and religious individual inform judgments about the behaviors of these individuals. We investigate this question in Study 2.

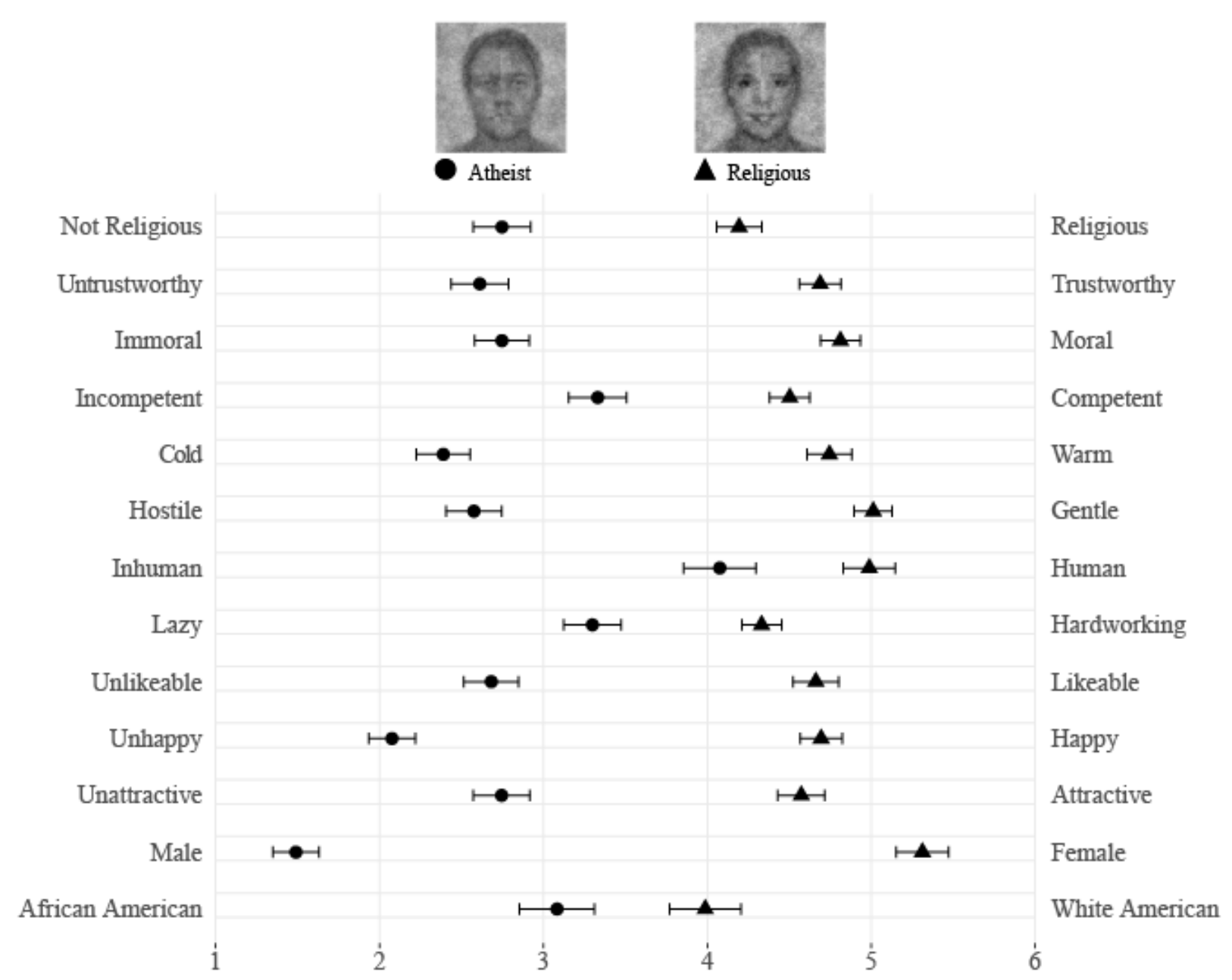

Figure 3. Ratings of the average atheist and religious image. Error bars represent $95 \%$ confidence intervals. 
Table 1. Mean, 95\% confidence interval, effect size, and Bayes Factor for each rating in Study 1.

\begin{tabular}{lcccccc}
\hline \multicolumn{2}{c}{ Atheist Image } & \multicolumn{3}{c}{ Theist Image } & & \\
Rating & Mean & $\mathbf{9 5 \%}$ CI & Mean & $\mathbf{9 5 \%}$ CI & $\boldsymbol{\eta}_{\boldsymbol{p}}{ }^{2}$ & Bayes Factor $_{\mathbf{1 0}}$ \\
\hline Religious & 2.75 & {$[2.57,2.92]$} & 4.19 & {$[4.06,4.33]$} & 0.50 & $1.48 \mathrm{e}+30$ \\
Trustworthy & 2.61 & {$[2.44,2.79]$} & 4.69 & {$[4.56,4.82]$} & 0.69 & $1.52 \mathrm{e}+55$ \\
Moral & 2.75 & {$[2.58,2.91]$} & 4.81 & {$[4.69,4.93]$} & 0.67 & $1.80 \mathrm{e}+57$ \\
Competent & 3.33 & {$[3.15,3.51]$} & 4.50 & {$[4.38,4.63]$} & 0.46 & $3.84 \mathrm{e}+22$ \\
Warm & 2.39 & {$[2.23,2.55]$} & 4.75 & {$[4.61,4.88]$} & 0.73 & $7.11 \mathrm{e}+63$ \\
Gentle & 2.58 & {$[2.41,2.75]$} & 5.01 & {$[4.90,5.13]$} & 0.76 & $9.41 \mathrm{e}+71$ \\
Human & 4.08 & {$[3.86,4.30]$} & 4.99 & {$[4.83,5.15]$} & 0.34 & $7.11 \mathrm{e}+13$ \\
Hardworking & 3.30 & {$[3.12,3.48]$} & 4.33 & {$[4.21,4.45]$} & 0.38 & $7.64 \mathrm{e}+17$ \\
Likeable & 2.68 & {$[2.52,2.85]$} & 4.66 & {$[4.52,4.80]$} & 0.66 & $1.68 \mathrm{e}+49$ \\
Happy & 2.08 & {$[1.93,2.22]$} & 4.69 & {$[4.57,4.82]$} & 0.78 & $6.10 \mathrm{e}+81$ \\
Attractive & 2.75 & {$[2.56,2.92]$} & 4.57 & {$[4.43,4.72]$} & 0.68 & $4.70 \mathrm{e}+44$ \\
Female & 1.49 & {$[1.35,1.63]$} & 5.31 & {$[5.15,5.47]$} & 0.87 & $3.08 \mathrm{e}+110$ \\
White & 3.08 & {$[2.85,3.31]$} & 3.99 & {$[3.77,4.20]$} & 0.22 & $3.98 \mathrm{e}+7$ \\
\hline
\end{tabular}

\section{Study 2 Method}

We used a within-subjects experimental design to investigate whether the mental images of the average atheist and religious individual inform judgments about the behaviors of these individuals. Participants were presented with two photos and read short scenarios describing moral and immoral behaviors. Participants were asked to determine which pictured person they believed was most likely to have done the behavior. On critical trials, the two photos were the average atheist and theist image. We hypothesized that participants would attribute immoral behaviors to the average atheist image and moral behaviors to the average theist image.

\section{Participants}

Given the within-subjects design, we needed at least 265 participants to have adequate power (.90) to detect a small effect $\left(f=.10 ; \mathrm{G}^{*}\right.$ power software; Faul et al., 2009). We recruited 296 American participants from Amazon Mechanical Turk. An attention check was included as the first question because past research suggests that such attention checks can improve data 
quality (Oppenheimer, Meyvis, \& Davidenko, 2009). Excluding participants who failed the attention check left a total sample of 273 (158 women, 114 men, 1 reported 'other'). ${ }^{5}$ The average age was 37.96 years $(S D=12.35)$, and 166 reported believing in God or a higher power (107 reported not believing in God or a higher power). All measures, manipulations, and exclusions are reported below.

\section{Procedure}

Participants were told that they would see read a short scenario describing one person's behavior and see pairs of "fuzzy" images of people. The scenarios represented both moral behaviors (e.g., "Left food out for a stray cat.") and immoral behaviors ("Kicked a dog for no reason;" for a full list of scenarios see the Supplementary Online Materials). On each trial, one scenario was presented with two images and participants were asked to determine which pictured person they believed was most likely to have done the behavior. Participants completed 10 critical trials (5 moral and 5 immoral scenarios) where the pictured people were the average atheist and religious images created in Study 1. Importantly, participants were not told how these images were created and there was no mention of religion or atheism. We also included filler images so that the comparison of interest would not be salient. For this reason, participants also completed 20 non-critical trials (10 moral and 10 immoral) were the pictured people were 4 randomly chosen stimuli used in the reverse correlations procedure in Study 1.

After the ratings, participants also reported whether or not they believed in God or a higher power. For exploratory purposes, we investigated whether participants' religious belief moderated our findings (see Supplementary Online Materials). Participants also completed

\footnotetext{
${ }^{5}$ Including all participants, even those who failed the attention check, does not substantively change the results.
} 
demographic information - age, gender, subjective SES, income, education, and race. These measures were collected to characterize the sample and will not be discussed any further.

\section{Results}

First, we averaged the number of times participants chose the average atheist image (1) versus religious image $(0)$ to create a proportion. Then, using a paired t-test, we investigated whether participants were more likely to choose the atheist image when the scenario was immoral. Consistent with our hypothesis, participants were significantly more likely to choose the atheist image when the scenario was immoral $(M=.83,95 \% \mathrm{CI}[.80, .86])$ than moral $(M=$ $.18,95 \% \mathrm{CI}[.15, .20]), t(272)=27.78, p<.001, M_{d i f} 95 \% \mathrm{CI}[.61, .70], \mathrm{BF}_{10}=5.45 \mathrm{e}+77$. Overall, the results provide overwhelming evidence that people's mental images of atheists and believers influences their perceptions of moral and immoral conduct.

\section{General Discussion}

The current research investigated whether people created biased mental images of atheists and theists. Consistent with our hypotheses, mental images of atheists appeared, to a naive sample, less trustworthy, moral, competent, and warm than mental images of theists. In addition, the average atheist image was rated as less likeable and attractive than the average theist image. Together, this suggests that negative stereotypes about atheists and religious individuals are represented in people's mental images of these two groups.

In addition, we found that these mental images influenced judgements of moral behavior. Participants were more likely to think the average atheist person committed immoral acts and the average religious person committed moral acts. Together, this suggests that mental images of theists are associated with more positive attributes than images of atheists, and these mental images influence perceptions of potential moral and immoral conduct. 
These findings are consistent with previous research investigating anti-atheist prejudice and pro-theist attitudes. People believe that atheists are untrustworthy (e.g., Gervais et al., 2011) and likely to commit immoral acts such as murder (Gervais, 2014). In addition, religious individuals, regardless of religious affiliation, are viewed as trustworthy (e.g., Hall et al., 2015). Our results extend those findings by suggesting that mental images of atheists and theists may be a subtle psychological mechanism reinforcing group stereotypes.

This research, however, is not without limitations. In particular, we utilized samples of convenience limited to individuals residing in the United States. These samples leave open questions about generalizability of the effect to other populations. Countries such as Finland and the New Zealand report very little anti-atheist prejudice relative to most other countries (Gervais et al., Invited Revision). We would expect these countries to perhaps have more neutral mental images of theists and atheists. Future research should investigate mental images of theists and atheists using representative samples inside and outside of the U.S.

\section{Conclusion}

Despite the wide range of religious diversity present in the U.S., there still exists at least one stark religious division: those who believe in God and those who do not. Although empirical data suggests that the relationship between religion and morality is complex, the present research presents a clear picture: people tend to imagine devilish atheists and angelic theists. These findings suggest that anti-atheist prejudice and pro-theist attitudes may be, at least in part, reinforced through biased mental images. Moreover, these biased mental images also influence judgements of behavior, with the majority of people believing that the average atheist mental image behaves immorally and the average theist mental image behaves morally. These mental images may contribute to the division between those who do and do not believe in God. 
Mental Representations of Atheists and Theists 18 


\section{References}

Bateson, M., Nettle, D., \& Roberts, G. (2006). Cues of being watched enhance cooperation in a real-world setting. Biology Letters, 2, 412-414.

Bering, J. M., McLeod, K. A., \& Shackelford, T. K. (2005). Reasoning about dead agents reveals possible adaptive trends. Human Nature, 16, 360-381.

Brown-Iannuzzi, J. L., Najle, M. B., \& Gervais, W. M. (In preparation). The Illusion of Political Tolerance: Social Desirability and Self-Reported Voting Preferences.

Cook, C. L., Cottrell, C. A., \& Webster, G. D. (2015). No good without God: Antiatheist prejudice as a function of threats to morals and values. Psychology of Religion and Spirituality, 7, 217-226.

Cottrell, C. A., Neuberg, S. L., \& Li, N. P. (2007). What do people desire in others? A sociofunctional perspective on the importance of different valued characteristics. Journal of Personality and Social Psychology, 92, 208-231.

Edgell, P., Gerteis, J., \& Hartmann, D. (2006). Atheists as "other"; Moral boundaries and cultural membership in American society. American Sociological Review, 71, 211-234.

Gallup. (2015). Religion. Retrieved from: http://www.gallup.com/poll/1690/Religion.aspx

Gervais, W. M. (2011). Finding the faithless: Perceived atheist prevalence reduces anti-atheist prejudice. Personality and Social Psychology Bulletin, 37(4), 543-556.

Gervais, W. M. (2013). In godlessness we distrust: Using social psychology to solve the puzzle of anti-atheist prejudice. Social and Personality Psychology Compass, 7, 366-377.

Gervais, W. M. (2014a). Everything is permitted? People intuitively judge immorality as representative of atheists. PLoS One, 9, 1-9. 
Gervais, W. M. (2014b). Perceiving minds and gods: How mind perception enables, constrains, and is triggered by belief in gods. Perspectives on Psychological Science, 8, 380-394.

Gervais, W. M., Shariff, A. F., \& Norenzayan, A. (2011). Do you believe in atheists? Distrust is central to anti-atheist prejudice. Journal of Personality and Social Psychology, 101, 1189-1206.

Gervais, W. M., Xygalatas, D., McKay, R. T., van Elk, M., Buchtel, E. E., Aveyard, M., Schiavone, S. R., Dar-Nimrod, I., Svedholm-Häkkinen, A. M., Riekki, T., Kundtová Klocová, E., Ramsay, J. E., \& Bulbulia, J. (Invited Revision). Nature Human Behavior.

Hall, D. L., Cohen, A. B., Mayer, K. K., Varley, A. H., \& Brewer, G. A. (2015). Costly signaling increases trust, even across religious affiliations. Psychological Science, 26, 1368-1376.

Inglehart, R., \& Norris, P. (2004). Sacred and secular: Religion and politics worldwide. Cambridge: Cambridge University Press.

Johnson, D. D. P., \& Bering, J. M. (2006). Hand of God, mind of man: Punishment and cognition in the evolution of cooperation. Evolutionary Psychology, 4, 219-233.

Love, J., Selker, R., Marsman, M., Jamil, T., Dropmann, D., Verhagen, A. J., Ly, A., Gronau, Q. F., Smira, M., Epskamp, S., Matzke, D., Wild, A., Knight, P., Rouder, J. N., Morey, R. D., \& Wagenmakers, E.-J. (2015). JASP (Version 0.7.1)[Computer software].

Morey, R. D., \& Rouder, J. N. (2015). BayesFactor (Version 0.9.11-3)[Computer software]. Murphy, C. (2016). Women generally are more religious than men, but not everywhere. Pew Research Center, Retrieved from: http://www.pewresearch.org/facttank/2016/03/22/women-generally-are-more-religious-than-men-but-not-everywhere/

Norenzayan, A., \& Gervais, W. M. (2013). The origins of religious disbelief. Trends in Cognitive Sciences, 17, 20-25. 
Norenzayan, A., Shariff, A. F., Gervais, W. M., Willard, A. K., McNamara, R. A., Slingerland, E., \& Henrich, J. (2014). The cultural evolution of prosocial religions. Behavioral and Brain Sciences, 1-86.

Rouder, J. N., Morey, R. D., Speckman, P. L., \& Province, J. M. (2012). Default Bayes factors for ANOVA designs. Journal of Mathematical Psychology, 56, 356-374.

Shariff, A. F., \& Norenzayan, A. (2007). God is watching you: Priming God concepts increases prosocial behavior in an anonymous economic game. Psychological Science, 18, 803809.

Simpson, J. A. (2007). Psychological foundations of trust. Current Directions in Psychological Science, 16, 264-268.

Sober, E., \& Wilson, D. S. (1998). Unto others: The evolution and psychology of unselfish behavior. Cambridge, MA: Harvard University Press.

Tan, J. H. W., \& Vogel, C. (2008). Religion and trust: An experimental study. Journal of Economic Psychology, 29, 832-848.

Todorov, A., Baron, S. G., \& Oosterhof, N. N. (2008). Evaluating face trustworthiness: A model based approach. SCAN, 3, 119-127.

Todorov, A., Olivola, C. Y., Dotsch, R., \& Mende-Siedlecki, P. (2015). Social attributions from faces: Determinants, consequences, accuracy, and functional significance. Annual Review of Psychology, 66, 519-545. 